\title{
Comunicación

\section{Ciudadanos de ficción: discursos y derechos ciudadanos en las telenovelas mexicanas. El caso Alma de Hierro}

Citizens of fiction: discourse and civil rights in Mexican telenovelas.

The Alma de Hierro case

DARWIN FRANCO MIGUES 1

Las telenovelas mexicanas han comenzado a "naturalizar" diversos derechos ciudadanos para construir un discurso social que, anclado al debate, busca promover la inhibición tanto del derecho como del ciudadano que lo ejerce. Este artículo aborda el análisis de la telenovela Alma de Hierro y la forma en cómo ésta representó la Ley de Interrupción Legal del Embarazo y la Ley de Sociedad de Convivencia.

PALABRAS CLAVE: Telenovelas, ciudadanía, derechos ciudadanos, representación.
Mexican soap operas have begun to incorporate notions of citizen rights within storylines anchored to contemporary public debate. Based on an analysis that followed the representation of abortion and alternative family formations in the soap opera Alma de Hierro, this paper argues that telenovelas' engagement with the public domain may hinder civil rights and the actors who pursue them.

KEY WORDS: Telenovelas, citizenship, civil rights and social representation.

1 Universidad de Guadalajara, México.

Correo electrónico: micorreoformal@hotmail.com

DECS, Paseo Poniente 2093, Jardines del Country, C.P. 44210; Guadalajara, Jalisco, México. 
¿Existen ciudadanos en las telenovelas? Es quizá la primera pregunta que se hace el lector de este artículo, conocedor -por herencia familiar o cultural- de que las telenovelas mexicanas nunca han sido productos televisivos donde la política, los problemas sociales y, mucho menos la ciudadanía, estén presentes.

Estos temas se hablan en géneros "serios" como los noticieros o programas de opinión; primero, porque es ahí -¿más que en otros sitios?- donde la audiencia se acerca para informarse y entender lo que sucede a su alrededor y, segundo, porque son este tipo de producciones, ¿y no otras? las que buscan "acercarse" al ciudadano para saber lo que opina o siente respecto de su realidad social.

Las telenovelas mexicanas, alejadas históricamente de esos objetivos, se han situado más en la frontera del entretenimiento y, por tanto, han permanecido (hasta ahora) al margen de la realidad político-social del país, pues difícilmente uno pensaría que en sus temáticas y narrativas abocadas plenamente al amor y al drama existen elementos para discutir las problemáticas contemporáneas que tanto aquejan y lastiman a los televidentes/ciudadanos que las miran y consumen.

Sin embargo, esto no quiere decir que antes las telenovelas excluyeran toda problemática social de sus narrativas; lo que sucedía es que su inclusión se concentraba en el espacio íntimo/privado de sus personajes, lo cual pocas veces dejaba entrever que lo que ahí sucedía tenía implicaciones en lo público.

Ahora aprovechando esa construcción íntima/privada, las telenovelas mexicanas, por la vía institucional o comercial, están creando una agenda específica que busca impactar a lo público desde las historias, situaciones y discursos de los personajes de ficción.

Esto es posible porque las telenovelas al ser el género televisivo más visto en México (IBOPE, 2010) tienen un papel muy importante en la generación y sostenimiento de diversos imaginarios individuales y colectivos.

En este sentido, sus narrativas hacen que lo "privado o personal sea político" (Benhabid, 2004), ya que a través de sus dramas y problemas de ficción se construyen referentes importantes para las audiencias. La matriz cultural que reside en las telenovelas, como explican diversos investigadores, posee una fuerza narrativa capaz de interpelar emocional 
y cognitivamente a los televidentes (González, 1998; Martín-Barbero \& Muñoz, 1992; Orozco, 2006; Vassallo, 2004); a tal punto, que muchos asumen, pese a lo ficcional, como realidad lo que pasa en la telenovela.

Esta interpelación, como explica Guillermo Orozco (2006), puede realizarse "burlando al género para acercarse a la realidad o burlando a la audiencia para acercarse al negocio puro" (p. 12). Lo cierto es que la importancia de la telenovela en el ámbito cultural e industrial propicia una serie de "prácticas de conocimientos y reconocimientos" (MartínBarbero \& Muñoz, 1992, p. 34) que se materializan en el cruce entre las lógicas comerciales y las lógicas que rodean a la producción y consumo de la telenovela.

Pero, ¿qué ocurre cuando este cruce explícitamente está buscando incidir en la opinión pública al incluir en las telenovelas posicionamientos sobre derechos ciudadanos, partidos y candidatos políticos, acciones gubernamentales o problemáticas sociales muy precisas, como el narcotráfico?, ¿qué implicaciones ocasiona que las telenovelas se estén usando para construir una agenda política?

Thomas Tufte (2007), investigador danés, precisa que la telenovela puede favorecer estas inclusiones debido a que su popularidad, en los países latinoamericanos, las vuelve un instrumento de educación "más importante y relevante que los programas noticiosos o la publicidad social" (p. 104). La telenovela y su capacidad para generar diálogo posibilitan romper el silencio, ya que colocan dentro de sus narrativas asuntos polémicos o tabúes, desafiando la moral, las normas y los valores sociales de determinada sociedad.

"La telenovela da visibilidad a ciertos asuntos, comportamientos, productos y no a otros; ella define una cierta pauta que regula las intersecciones entre la vida privada y la pública" (Vassallo, 2004, p. 74). La anterior cita, ejemplifica el poder narrativo de la telenovela al volverse lugar de referencia, no sólo de los diálogos cotidianos de quienes disfrutan tanto hablar de la telenovela como de verla, sino también de los debates sociales al concentrar en sus narrativas problemas políticosociales que se colocan en la esfera pública gracias a la representación privada que hace la telenovela de los mismos.

Al hacer esto, para María Immacolata Vassallo, la telenovela ejerce una función de agenda setting (McCombs \& Shaw, 1972), pues incor- 
pora temas del ámbito público en sus narrativas -teóricamente- dirigidas al universo privado.

"La fusión de las esferas privadas y públicas que realiza la telenovela permite sintetizar problemáticas amplias en figuras y tramas puntuales $\mathrm{y}$, al mismo tiempo, sugerir el que dramas personales lleguen a tener un significado amplio" (Vassallo, 2004, p. 88). Dicho significado adquiere un valor importante en las telenovelas, y a diferencia de las agendas que se generan en los noticieros, en la ficción no sólo se incluye el "qué pensar" sino que se nos invita a "sentir y vivir" lo representado, creando amplios significados que vehiculan problemáticas sociales complejas con soluciones personales que ofrecen a la audiencia uno o varios ejemplos de cómo se debe pensar, actuar y sentir en caso de padecer o vivir una situación similar.

En este artículo, específicamente, se abordará la manera en que la telenovela Alma de Hierro (Televisa, 2009), vía esa agenda, fue capaz de construir una posición frente a la ciudadanía y lo que significa ser ciudadano al introducir intencionalmente en sus temáticas la Ley de Interrupción Legal del Embarazo (LILE) y la Ley de Sociedad de Convivencia (LSC).

\section{LAS TELENOVELAS EN MÉXICO}

¿UNA NUEVA AGENDA POLÍTICA?

Ideadas, producidas y materializadas bajo el "modelo Televisa", como lo ha establecido la investigadora argentina Nora Mazziotti (1996, 2006), ${ }^{2}$ las telenovelas mexicanas se han realizado en un esquema donde esencialmente reinan los aspectos melodramáticos, sentimentales, maniqueístas e, incluso, los vinculados a la moral religiosa por encima de los temas sociales o políticos.

Tal fue su desarraigo que hasta $1996^{3}$ las telenovelas no presentaron

2 La investigadora engloba a la industria y producción de telenovelas en América Latina mediante seis modelos: argentino, venezolano, colombiano, Miami (Estados Unidos), brasileño (Tv Globo) y mexicano (Televisa).

3 Fecha paradigmática, ya que fue el año en que Televisa perdió el monopolio de la ficción al estrenarse en las pantallas de TV Azteca la telenovela Nada 
vínculos explícitos a la realidad social que intentaron representar, ya que en sus historias no existían ni país ni ciudades reconocibles.

Sus pilares narrativos históricos como: la familia nuclear (padre, madre e hijos), el drama del reconocimiento, el ascenso social, la imagen de la mujer abnegada $\mathrm{y}$, sobre todo, los preceptos católicos no habían permitido la creación de temáticas que, justamente, fueran contrarias a esa realidad ficcional, pues de manera constante los dramas de las telenovelas buscaban desviar la mirada de lo social/real, como reiteradamente lo ha mencionado la propia Nora Mazziotti.

Sin embargo, lo que sucede hoy en día en las telenovelas mexicanas está muy lejos de esa aparente ingenuidad o total desvinculación de lo social, ya que existen indicios importantes y constantes para reconocer que la telenovela en México se está reconfigurando industrial y culturalmente.

Actualmente por las narrativas de la ficción mexicana se promocionan no sólo productos comerciales de toda índole y en todo momento (dentro y fuera de la telenovela, con menciones directas o indirectas de sus personajes e, incluso como parte de la trama narrativa), ${ }^{4}$ sino que también - por la vía comercial- se presentan, promocionan y discuten derechos y obligaciones ciudadanas, programas públicos, logros gubernamentales, ${ }^{5}$ partidos políticos y políticos devenidos en actores.

personal, producción que rompió la barrera entre la realidad y la ficción al crear una historia sobre los vínculos de corrupción entre la clase política y el crimen organizado (Dorcé, 2005). Esta fue la primera telenovela mexicana donde México y sus instituciones aparecieron. Un año más tarde, Mirada de mujer (1997), también acabó con el tradicional melodrama mexicano al presentar una historia donde una mujer madura se enamora de un hombre joven.

4 Las telenovelas de Televisa Hasta que el dinero nos separe (2010) y Una familia con suerte (2011) llevaron al extremo la inclusión de la publicidad al hacer de ésta parte integral de su narrativa. En la primera telenovela, la marca Ford aparecía como un personaje más al desarrollarse toda la historia en una agencia de autos. En Una famila todo sucede dentro de la empresa de cosméticos Avon.

5 El caso más polémico de la incorporación de publicidad gubernamental es la serie El equipo (Televisa, 2011), producción grabada en las instala- 
La reciente incorporación del marketing político en la ficción televisiva y las implicaciones que esto conlleva se entienden mejor en el clima político generado por la Reforma Electoral del año 2007. Legislación que prohibió a los partidos políticos mexicanos la contratación de spots en medios de comunicación.

Con las modificaciones es el Instituto Federal Electoral (IFE) -y no los partidos políticos- quien se encarga de otorgar y distribuir, en tiempos oficiales y fiscales, los espacios para que éstos tengan presencia y visibilidad mediática. ${ }^{6}$

La erradicación del principal vehículo para el debate político en los medios (los spots) ha permitido a las televisoras explorar y materializar en otros formatos sus posturas político-ideológicas. En este sentido, la propaganda disfrazada en las telenovelas, no contemplada en la ley, se han convertido en un fértil terreno para que las televisoras, el gobierno y los partidos políticos "naturalicen" sus ideas, propuestas y logros dentro de la trama e intimidad de los personajes de ficción.

De ahí que de forma paulatina y constante en las narrativas de la ficción mexicana se han asomado con o sin contextualización problemáticas como: la violencia social, el narcotráfico, la corrupción, los matrimonios gay, el aborto, la renta de vientre, la trata de blancas, la promoción de candidatos y acciones emprendidas por diversos gobiernos estatales y municipales, entre otros. ${ }^{7}$

ciones de la Policía Federal y que construyó en su narrativa una historia que pretendió cambiar la percepción pública de la estrategia gubernamental contra el crimen organizado (narcotráfico). En esta serie, el gobierno federal invirtió 118 millones 116 mil pesos.

6 Con esto se mermó no sólo el capital financiero de los medios mexicanos, principalmente del duopolio televisivo: Televisa y TV Azteca, sino también su capacidad simbólica para influir de esta manera en las elecciones y en la política.

7 En este rubro destacan el proselitismo que se hizo en la telenovela La fea más bella (Televisa, 2006) a favor del ahora presidente de México Felipe Calderón; la promoción de las plataformas políticas del Partido Verde Ecologista de México en las telenovelas Un gancho al corazón (2009) y Triunfo del amor (2011), ambas producciones de Televisa; el anuncio -durante una 
Estas modificaciones narrativo-temáticas no sólo han propiciado un cambio de 360 grados en el modelo Televisa (Orozco, Huizar, Franco \& Hernández; 2010), sino también han permitido observar que dichas configuraciones no sólo atañen a las propias televisoras que hasta ahora se dividen el mercado de la ficción en México, (Televisa y TV Azteca), sino también a diversas instancias gubernamentales, partidos políticos y empresas que fuera de ellas inciden y pujan desde lo comercial e institucional para que éstas incluyan a la realidad social como motor narrativo.

Este texto propone que dichos cambios se están realizando desde tres dimensiones que interna o externamente han influido para que las telenovelas mexicanas rompan su modelo histórico de producción:

1. Dimensión político-institucional. Modificaciones legales que han orillado a las televisoras a buscar nuevos formatos para naturalizar tanto sus posturas político-ideológicas como para comercializar la publicidad política.

2. Dimensión económica. Estrategias mercantiles que han incidido como unidades significativas en los cambios narrativos/temáticos. Técnicas como brand placement, product placement, merchandising social, engagement y marketing político han modificado la telenovela al introducir en ella no sólo publicidad comercial sino también política y gubernamental.

3. Dimensión narrativa: Mutaciones/cambios en las temáticas producto de la apertura de los mercados globales de la ficción. Esto ha potencializado la estandarización de los contenidos y la adaptación/apertura hacia nuevas temáticas que escapan de lo local para incorporarse a los gustos globales (Franco, 2010, p. 85).

A través de estas dimensiones se busca precisar que las telenovelas mexicanas están en plena reconfiguración, lo cual no significa el abandono del modelo Televisa; al contrario, se considera que éste se ha adaptado a los nuevos tiempos ficcionales que amenazan con cubrir de publicidad y política sus narrativas.

semana de transmisión- de los logros del gobierno de Chiapas en la telenovela de TV Azteca, Pasión morena (2009). 
Este artículo sostiene que las televisoras mexicanas están apostando a la ficción como una nueva manera de fijar la "agenda", una agenda no sólo racional (si así se le quiere ver) sino fundamentalmente sentimental. Esta agenda ficcional ha roto su cerco narrativo y simbólico para adentrarse a la discusión pública de múltiples problemáticas sociales porque ahora sus referentes ya no son únicamente ficcionales, sino que cada vez éstos tienen que ver con situaciones reales que se discuten en el nivel social, político, cultural y, desde luego, mediático.

Esta agenda ficcional, como se establece en las dimensiones que se proponen para entender el cambio en las telenovelas mexicanas, hace evidente que detrás de esas historias dramáticas y sentimentales se esconde un sentido político-económico que de forma velada trata de colocar en las audiencias mensajes y moralejas sociales que podrían ser más contundentes que la información "objetiva" de los noticieros.

\section{LA REPRESENTACIÓN CIUDADANA \\ EN LAS TELENOVELAS MEXICANAS}

Con relación a la agenda que ahora construyen las telenovelas, éstas han buscado ser un mejor y más emotivo canal para la discusión privada y pública de diversos derechos ciudadanos que tras su aprobación se han vuelto polémicos; tal y como sucedió con la aprobación de las leyes de Interrupción Legal del Embarazo (LILE) y de Sociedad de Convivencia (LSC), aprobadas en la Asamblea Legislativa del Distrito Federal (ALDF) en noviembre de 2006 y abril de 2007, respectivamente.

Esto no significa que el elemento ciudadano estuviera erradicado o vetado en las telenovelas mexicanas anteriores a 1996, 8 sino que la propuesta existente era más bien pasiva y acrítica.

No obstante, la telenovela ha fungido como un elemento clave en la conformación de ciudadanos porque éstas desde su narrativa influyen al:

- Privilegiar al espacio privado como único lugar de referencia. Automáticamente se excluye cualquier otro tipo de espacio o escena-

8 Año en que se transmitió Nada personal y que significó la apertura de la telenovela a la realidad social (Dorcé, 2005). 
rio social colectivo o público. No se niega su existencia de manera explícita, pero no se menciona ni se refiere, anclando la trama en el único espacio privilegiado: el íntimo-privado.

- Visibilizar u ocultar problemáticas obstaculizando el debate público. La manera de ventilar, discutir y solucionar las problemáticas ficcionales se hace en una sola dimensión: la afectiva y/o la privada. Pareciera que en ella todo es cuestión de amores, de afectos y no de hechos ni de responsabilidades ciudadanas.

- Exhibir o inhibir derechos y obligaciones propiciando el respeto, conocimiento, cumplimiento o incumplimiento de los mismos. En la telenovela no hay nada escrito ni reglas ni leyes que trasciendan la trama misma y a sus personajes, sino que todo queda a la deriva de la circunstancia afectiva.

- Promover acciones de inclusión o exclusión de manifestaciones sociales diversas. La racionalidad o la "figura de razón" que opera en muchos de los juicios no tienen nada que ver con un código de ética $\mathrm{y}$ a veces ni siquiera con una moralidad católica, sino que se nutre de juicios y nociones diversas que emergen y se justifican en aspectos afectivos de la narrativa de las telenovelas (Franco \& Orozco, 2010; p. 81).

Estos factores se suman a las posiciones abiertas y activas con las cuales las telenovelas mexicanas actualmente comienzan a posicionar en sus narrativas y temáticas determinados derechos ciudadanos que sirven - de texto y pretexto- para discutir y proponer desde la ficción su alcance y validez a través de representaciones ficcionales que conforman discursos ciudadanos capaces de conjuntar la acción de sus personajes con los sentires políticos, sociales y mediáticos generados en relación a la discusión pública del derecho representado.

Por tanto, aquí se entenderá al concepto de representación como el modelo creado, elaborado y compartido en el nivel social que permite a los individuos crear un patrón mental, sentimental y racional respecto de algún objeto o situación (Rodríguez, 2009). Si bien estas representaciones son esquemas socioculturales, es mayoritariamente por los medios que las audiencias construyen y reconstruyen esos esquemas al compararlos con las nuevas imágenes que de ellos y otros surgen en los diversos formatos y contenidos mediáticos. 
En consecuencia, una representación ciudadana, dentro de la ficción, será el modelo que se construya con relación al personaje que manifieste abierta o parcialmente su interés por materializar o inhibir algún derecho u obligación, ya sea para sí mismo o en función de las problemáticas de un tercero. Para fines de este artículo propongo nombrar a esta representación ciudadano de ficción.

\section{CIUDADANÍA UN BREVE RECORRIDO}

¿Qué es la ciudadanía y qué significa ser ciudadano? Es la interrogante que ha intentado responder la teoría política desde tiempos de los griegos y de la que ahora se tienen diversas y múltiples concepciones que ahondan, ya no sólo el campo de lo jurídico-político, sino también en lo cultural/comunicativo.

La ciudadanía ha sido explicada desde su estado natural; por ejemplo, Aristóteles consideraba que el zoon politikon (el hombre) es un animal político y, por ende, en su génesis es un ciudadano que busca incidir en la plaza pública; por otro lado, los romanos, en específico Cicerón, consideraban que el hombre es una entidad jurídica, y, como ciudadano, contrae sólo una relación legal con el Estado.

Ambas percepciones, vigentes hoy en día, han hecho que la jurisprudencia transforme el concepto de ciudadano del "zoon politikon al legalis homo" (Pocock, 1995, p. 38), lo que en consecuencia lo ha identificado, en cierto modo, "más como un votante que como un animal político" (Heater, 2007, pp. 15-16).

Esta reconfiguración jurídico-política de lo que implica ser un ciudadano se ha trasladado hasta nuestros días bajo la visión del pensamiento liberal, donde se sitúa al sujeto social al centro de la interacción sociopolítica, y el pensamiento republicano, donde se confiere a éste una relación de derechos y obligaciones con base en su pertenencia a una colectividad o sociedad.

Otra postura política, como el "comunitarismo cívico", propone mirar a la ciudadanía en función de las vinculaciones sociales, el carácter social del ciudadano y sus lazos de pertenencia, no tanto con relación a los aspectos jurídico-políticos, ya que el foco está en las acciones comunitarias que se hacen en pro del "bien común" por encima de los derechos (Ramírez Sáiz, 2007, p.16). 
Hasta nuestros días, estas corrientes políticas se han convertido en las matrices teóricas desde donde se define lo qué es la ciudadanía y cuáles son los procesos que intervienen en la construcción de la misma.

T. H. Marshall en su obra Ciudadanía y Clase Social (1998) sentó los antecedentes para entender de manera más compleja a la ciudadanía y sus distintas dimensiones. El teórico inglés propuso mirar a la ciudadanía a través de una estrategia teórica de rango medio en las que las unidades de análisis son estructuras sociales específicas; con ello no sólo separó a la ciudadanía de una concepción netamente jurídica sino que la ancló a una dimensión histórica distribuida en tres dimensiones: civil, política y social.

El elemento civil se compone de los derechos necesarios para la libertad individual, así como de las obligaciones que derivan de éstos; la dimensión política implica el derecho a participar en el ejercicio del poder (votar y ser votado) $\mathrm{y}$, por último, la social -vinculada al estado de bienestar-contempla que los ciudadanos deben recibir por parte de su gobierno: trabajo, seguridad, vivienda, educación y salud. A través de estas dimensiones, Marshall explicaba que la ciudadanía es un proceso sociocultural evolutivo e irreversible con una función integradora que trata de disminuir la distancia entre las clases sociales (Marshall, 1998, p. 20).

No obstante, la distancia entre las clases no ha disminuido ni tampoco el avance jurídico-político de la ciudadanía ha significado un real y equitativo ejercicio de ésta, al menos no desde las dimensiones plasmadas por Marshall, ya que por la "vía de los hechos se han generado terribles y dolorosas exclusiones, desigualdades e injusticias que anteceden a la formalización política, pero que se agudizan en esos territorios" (Reguillo, 2003, p. 28).

Esto sucede así porque el concepto de ciudadanía, en la práctica, se ha vaciado a su manifestación electoral dejando fuera su dimensión civil, ha cambiado y reducido la participación ciudadana por la organización partidista olvidando su dimensión política y, finalmente, su dimensión social ha quedado a merced de lo que los ciudadanos puedan hacer frente al consumo y a los mandatos de los nuevos poderes económicos (Cortina, 2003).

No obstante, el modelo clásico de ciudadanía se ha reestructurado y ha incluido dos nuevas dimensiones: la económica y la cultural. La primera se enfoca en garantizar la participación de los individuos en 
las decisiones sobre economía que afectan a su comunidad política y la segunda, implica entender a la ciudadanía como una relación entre ciudadano/ciudadano (y no ciudadano/Estado), donde el reconocimiento de lo distinto y diverso, culturalmente hablando, va más allá del reconocimiento legal (Rosaldo, 1994).

Esta última dimensión, la cultural, representa un cambio importante para la ciudadanía, ya que al devolverle su plataforma cultural -erradicada u olvidada por el determinismo jurídico-político- se ha puesto en debate las pertenencias y adscripciones de lo que significa ser un ciudadano. Para Renato Rosaldo (1994), uno de los principales impulsores de la ciudadanía cultural, esto significaría poner "sobre la base común del mantenimiento de las distintas identidades, el ejercicio de una 'participación plena' en la comunidad en su conjunto, para así establecer puentes entre la diferencia y la homogeneidad social y cultural" (p. 402).

En la realidad son los ciudadanos (y el entorno institucional que los rodea) los que determinan el ejercicio y validación de los derechos y obligaciones para sí mismos y para otros, ya que son ellos quienes articulan la organización, expresión, participación y representación social a partir de "las pertenencias y anclajes culturales, el género, la etnia, la religión, las opciones sexuales y las múltiples adscripciones identitarias, ente otras" (Reguillo, 2003, p. 36).

Lo anterior será un elemento clave para analizar las formas culturales y simbólicas que de la realidad se extraen para representar en las telenovelas de una mejor manera las expresiones ciudadanas con relación a los derechos y obligaciones que dentro de ellas ejercen, promueven o inhiben sus personajes.

Para ubicar en la ficción, tanto los elementos ciudadanos reales como las formas culturales y simbólicas que los materializan, se usó el esquema teórico-metodológico del investigador mexicano Juan Manuel Ramírez Sáiz (2007), quien "sitúa y ubica” al concepto de ciudadanía en:

- Ejes estructurantes: jurídico-político, socioantropológico e institucional.

- Dimensiones implicadas: civil, política, social, económica y cultural.

- Procesos instituyentes de derechos: defensa, ampliación e innovación. 
- Ámbito de vigencia y ejercicio: local, nacional o global.

- Referentes teóricos: liberal, comunitaria y republicana.

En su modelo, Ramírez Sáiz precisa que hay una oposición y polarización entre quienes ven a la ciudadanía desde un aspecto jurídico-político (derechos y obligaciones) y quienes apuestan más por su lado socioantropológico (identidad, sentido de pertenencia a una comunidad, prácticas sociales para ejercer los derechos y cumplir las responsabilidades, etc.), a éstas les añade el eje "institucional" que son aquellos documentos legales que protegen los derechos y regulan las obligaciones (constituciones, leyes, tratados, reglamentos, etc.). Para Ramírez Sáiz (2007) estos ejes estructurantes se conjuntan y entraman, pues "desde un punto de vista genético o diacrónico, los derechos y la ciudadanía se inician como prácticas sociales, después se legalizan como estatus y finalmente se materializan a través de las instituciones" (p. 10).

Al construirse a través de las prácticas sociales, la ciudadanía va evolucionando conforme los cambios sociopolíticos y sus elementos estructurantes, por lo que no puede separarse a la ciudadanía de la lucha histórica por "el derecho a tener derechos" (p. 11), de ahí la importancia de los procesos que la instituyen: defensa (lucha por el reconocimiento y restitución de los derechos, así como la exigencia para que el Estado cumpla sus obligaciones); ampliación (extensión de los derechos existentes), e innovación (búsqueda por el reconocimiento legal de nuevas manifestaciones sociales y creación de nuevos derechos y obligaciones que no están contenidos en las leyes).

A continuación, se expone de manera sucinta cómo este modelo se adaptó al análisis de las representaciones ciudadanas presentes en Alma de Hierro.

Los ejes estructurantes jurídico-político, socioantropológico e institucional fueron usados para analizar las formas y estructuras desde las cuales la telenovela ancló la existencia de los derechos. En este sentido, lo jurídico-político estuvo representado por los elementos que dentro de la trama se vincularon con los procesos y derechos; lo socioantropológico fue la forma en que las prácticas ciudadanas se materializaron al construir situaciones en las cuales el ámbito sociocultural determinó los motivos y acciones de los personajes que buscaban validar sus de- 
rechos, y por último, la parte institucional sirvió para identificar a las instituciones que dentro de la ficción se presentaron como entidades que pueden validar y/o resguardar los derechos.

Las dimensiones ciudadanas, a través de la dimensión civil se tomó como el eje central del análisis, pues permitió analizar cómo se construyó el discurso ciudadano con relación a la acción que los personajes asumieron para manifestar que tienen derecho a determinada cosa y, que por tanto, el otro está obligado aceptarla. Ahí se da la conexión con la dimensión cultural, ya que se buscó saber bajo qué términos y valores un personaje puede ser acreedor a un derecho o por qué, bajo esas mismas circunstancias, éste puede ser limitado por sí mismo o por la presencia de otro personaje que le recuerda los valores aceptados en la ficción. ${ }^{9}$

Los procesos instituyentes de defensa, ampliación e innovación sirvieron para reconocer cuál fue la finalidad de representar tanto la LILE como la LSC dentro de Alma de Hierro. Mediante éstos se reconoció si lo plasmado en la telenovela contribuyó a defender, ampliar o innovar los derechos o si, en su defecto, la representación se encaminó más a su inhibición. Esta nueva categoría fue agregada para dar cuenta de un proceso instituyente que desde la construcción mediática contribuyó más al detrimiento de los derechos que a su valorización.

Por tanto, un ciudadano de ficción será aquella representación ficcional que alude: a) a la dimensión civil de la ciudadanía para exigir y validar el ejercicio de sus derechos y el cumplimiento de sus obligaciones, y b) a la dimensión cultural para jerarquizar, otorgar, validar, intervenir y asesorar en el uso de los derechos/obligaciones de otros personajes.

En este sentido, el concepto de ciudadanía cultural es clave para entender cómo desde la ficción se recrea/representa una plataforma cultural y simbólica que pone a discusión la consideración de las pertenencias y adscripciones desde las cuales se nutren las representaciones ciudadanas que la ficción intenta plasmar.

9 A su vez éstas fueron las dimensiones más reiterativas dentro de la observación general que se hizo de la ficción mexicana (junio 2008/marzo 2010) y al interior de la propia narrativa de Alma de Hierro, caso de estudio del presente texto. 
El objeto central de este texto es analizar cómo los dispositivos de representación mediática contribuyen a la definición de los ciudadanos de ficción a través de las prácticas que realizan y los discursos con los que sustentan la acción o inacción de sus derechos/obligaciones dentro de la narrativa de Alma de Hierro.

\section{ALMA DE HIERRO, EL ESTUDIO DE UN CASO PECULIAR}

Alma de Hierro fue una telenovela mexicana que se transmitió en Televisa entre los años 2008 y 2009. Basada en el teledrama argentino Son de Fierro (2007) y dirigida por Roberto Gómez Fernández, hijo del célebre cómico Roberto Gómez Bolaños, "Chespirito", esta producción fue importante, ya que modificó la tradicional manera en que Televisa producía sus telenovelas, tanto en formatos como en contenido.

Para empezar su formato era de media hora (y no de una hora como históricamente se ha realizado), se transmitía justo antes de la barra informativa y poseía una narrativa peculiar que rompía aparentemente con las historias rosas al presentar como personaje principal no a una mujer sino a un hombre, José Antonio Hierro, quien asume el cuidado de la familia cuando su mujer deja el hogar para irse con un hombre joven.

Alma de Hierro, en sus dos años al aire, mantuvo altos niveles de rating. En 2008 se colocó como la quinta telenovela más vista con 22.6 puntos; en 2009 subió al cuarto lugar aunque decreció en rating al tener 19 puntos (IBOPE, 2009).

No obstante, la mayor particularidad de Alma de Hierro fue que dentro de su narrativa se desarrollaron y pusieron en debate diversos temas ciudadanos como: la discapacidad, la homosexualidad, el aborto, la eutanasia, la patria potestad y la separación de bienes, todos ellos derechos ciudadanos. ${ }^{10}$ Lo distinto es que éstos no sólo se nutrieron del elemento "sentimental", sino que a su vez tomaron a la realidad y sus leyes como un factor narrativo importante que cambió tanto la vinculación de la realidad con la ficción como el sentido pasivo y acrítico de las representaciones ciudadanas existentes en las telenovelas mexicanas.

10 Estos temas surgieron del análisis de contenido temático que se realizó con la telenovela durante toda su transmisión. 
Esta vinculación con la realidad fue importante porque Alma de Hierro introdujo intencionalmente dichas temáticas para conectarse con la opinión pública que en ese momento discutía, fuera de la telenovela, la validez o no de los derechos ciudadanos que ésta tomó como motores narrativos. 11

Relacionando los diversos temas ciudadanos presentes en Alma de Hierro, aquí se optó por elegir el tema del aborto y la unión civil de personas del mismo sexo debido a que estas temáticas se presentaron en la telenovela en momentos cruciales donde fuera de ésta se discutía su constitucionalidad y vigencia, motivo que llevó a la ficción a desarrollar amplias historias con relación a estos derechos.

\section{ALMA DE HIERRO, UNA MANERA DE CREAR \\ UNA AGENDA CIUDADANA DESDE LA FICCIÓN}

No todos los derechos ni todas las prácticas y discursos ciudadanos están presentes en las telenovelas mexicanas, pues su visibilidad mediática depende en gran medida de la importancia de los derechos o del revuelo político-social que generen a su alrededor. Esto aún cuando su ejercicio y validación sólo sean efectivos en determinado territorio.

Para efectos del texto he de centrarme específicamente en las representaciones que se hicieron de la LILE y la LSC dentro de Alma de Hierro. Estas legislaciones consideradas como las más vanguardistas del presente siglo en México también han sido las más controvertidas porque expusieron pública y mediáticamente la polarización social que existe cuando la acción jurídica intenta legislar sobre situaciones o problemáticas que contravienen las posturas conservadoras de los grupos de poder político, económico y religioso.

Ambas legislaciones fueron aprobadas en el Gobierno del Distrito Federal (GDF), que desde los años noventa es gobernado por la izquier-

11 Es para señalar que esta intencionalidad temática puede corroborarse, ya que en la versión original, Son de fierro, ninguno de los temas señalados se desarrolla con la misma vinculación a la realidad; pues nunca se expone plenamente el derecho del aborto ni existe una boda gay como sucedió en el final de la versión mexicana. 
da mexicana representada por el Partido de la Revolución Democrática (PRD). Sin pretender extender o agotar la disputas ideológicas entre el GDF y el gobierno federal que encabeza la derecha mexicana a través del Partido Acción Nacional (PAN), se puede afirma que este choque de ideas es lo que más dio revuelo a la aprobación de LILE y la LSC, pues la principal oposición se dio por parte de los gobiernos del PAN, quienes llevaron a la Suprema Corte de Justicia de la Nación (SCJN) la validez constitucional de ambos derechos.

Cuestión sin duda relevante ya que la discusión que se dio en Poder Legislativo y en la SCJN fue lo que hizo coincidir en tiempo y forma la representación que Alma de Hierro hizo de ambas legislaciones. Pese a los recursos interpuestos, la SCJN declaró la constitucionalidad de la LILE y la LSC. 12

No obstante estas resoluciones, lo ocurrido en Alma de Hierro evidenció la manera en que la ficción se está usando como una "agenda", donde pese a la legalidad de los derechos, se construye un mensaje y moraleja que expone a las audiencias que dentro y fuera de la telenovela existen diversos valores morales y sociales que son más importantes que la propia ley y sus ciudadanos.

\section{CÓMO MIRAR LO CIUDADANO EN LA FICCIÓN:}

UNA PROPUESTA INTERTEXTUAL

Este artículo contempló a la telenovela no sólo en lo simbólico sino también en lo sociohistórico, conjuntando el análisis contextual desde donde se gesta el discurso-narración de la telenovela con el análisis de la estructura simbólico-discursiva que se construyó en la narrativa de Alma de Hierro.

12 Tras la declaración de constitucionalidad de la LILE en el Distrito Federal, 17 estados han legislado de forma contraria, pues han establecido que el "respeto a la vida" -que va desde la concepción hasta la muerte naturaldebe ser respetado; por tanto, la mujer que ose interrumpirlo será sujeta de sanciones penales. Con relación a la LSC, ningún otro estado había legislado en la materia hasta que la ALDF aprobó, el 21 de diciembre de 2009, el matrimonio civil entre personas del mismo sexo. 
Para realizar esto se uso el método del Análisis Crítico del Discurso (ACD) de Norman Fairclough (2008). Este análisis, específicamente, se empleó para analizar las interacciones ideológicas que se establecen entre los discursos de la telenovela y los discursos intertextuales que, desde fuera, sirven de insumo narrativo.

Norman Fairclough establece que el ACD debe realizarse en un encuadre donde cada evento discursivo tiene tres dimensiones: a) texto (oral, escrito o audiovisual), b) práctica discursiva (producción e interpretación del discurso) y c) práctica social (materialización del discurso). Dichas dimensiones están interconectadas por las condiciones sociales e históricas de la producción, circulación y recepción de las formas simbólicas.

Por tanto, el estudio que se presenta de la telenovela Alma de Hierro es un análisis del discurso ${ }^{13}$ que se generó con relación a la LILE y la LSC, y las interconexiones contextuales e intertextuales que desde la telenovela (en cuanto texto) permitieron correlacionar la representación de los derechos con las dimensiones, los procesos instituyentes y los ejes estructurantes de la ciudadanía. Tal y como se explicó líneas atrás al asumir el modelo de Ramírez Sáiz como sustento teórico-metodológico para unir ciudadanía y telenovela.

Enseguida se aborda de forma particular los análisis discursivos e intertextuales de la LILE y la LSC. Esto se hará uniendo el ACD realizado a diversos fragmentos de cada temática con los discursos intertextuales (contexto) que ayudaron a enfatizar el papel y la postura que desde Alma de Hierro se construyó al respecto.

\section{LILE: "ABORTEMOS LA LEY, NO LA VIDA"}

Esta ley válida sólo para la capital del país fue aprobada por la ALDF el 24 de abril de 2007. Sin embargo, diversos recursos de anticonstitucionalidad extendieron por más de un año la discusión social y mediática

13 Pese a ser un producto televisivo, los elementos iconográficos fueron incorporados únicamente como "ancla de sentido" para reconocer y afianzar los elementos discursivos que no podrían ser comprendidos sin su complemento visual. 
del tema y no fue hasta el 28 de agosto de 2008 que la SCJN determinó declarar la constitucionalidad de la Ley.

Cuando esto sucedió, nuevamente, las campañas "a favor de la vida" (como "En México elegimos la vida" encabezada por la Iglesia Católica, 01/09/08) coparon las pantallas televisivas del país, sólo que esta vez trasladaron el debate al terreno de la emotividad al incluir a la LILE dentro de la telenovela Alma de Hierro.

\section{¿OPCIÓN NARRATIVA O COYUNTURA FICCIONAL?}

La historia dentro de esta telenovela está protagonizada por Sandy Hierro una joven de entre 20 y 22 años ${ }^{14}$ que se enamora de Amadeo, empleado de confianza de su padre y esposo de Maribel, amiga de la familia. Ambos tienen un hijo en común: Pedrito.

El amor que Sandy siente hacia Amadeo es tan fuerte que decide entablar con él una relación extramarital. Al ser descubierto su romance, éstos como acto de despedida deciden entregarse con el juramento de que después cada quien seguiría con su vida. Sin embargo, tras esa entrega, Sandy resultó embarazada.

Esta trama se trasmitió del 1 al 22 de octubre de 2008, justo un mes después de que la ley fuera declarada constitucional. En la trama, Sandy es acompañada y apoyada por Ignacio y Ary; ambos le indicaron "el deber ser", a la par que la orientaron en función del derecho ciudadano que ésta pretendió ejercer y validar en la ficción.

\section{La opción narrativa}

Sandy decide esconder su embarazo por la vergüenza y malestar que le provoca ser madre soltera y porque no quiere que esto destruya a la familia de Amadeo. Cuestión que se hace evidente en el siguiente diálogo entre Sandy (S) y Ary (Ar):

14 Sandy personifica al tipo de mujer que más ha acudido a las clínicas para interrumpir su embarazo, ya que acuerdo a la Secretaría de Salud del Distrito Federal, la descripción de la mujer promedio que ha abortado oscila entre 18 y 24 años (46.6\%), cuenta mayoritariamente con estudios de preparatoria (34.9\%) y es soltera (54\%). Información hasta el 22/04/2010. 
S: Tantos años teniendo la ilusión de lo que iba a sentir el día me que dijeran que iba a ser madre y ahora que lo compruebo me siento muy mal.

Ar: Pues vas a tener que superar esa situación porque: jvas a ser madre!

S: Pero no soporto la idea de ser madre sin un padre de por medio.

Capítulo 159 (03/10/08).

Ser madre "sin padre" no es una opción narrativa viable dentro del modelo Televisa; por ello, Sandy ha perdido toda la "ilusión" de la maternidad, pues no es lo figurativo lo que lastima e incómoda sino lo simbólico, ya que lo "insoportable" es no poder cumplir el sueño de toda mujer: crear y tener una familia.

Sin embargo, la telenovela quería orillar narrativamente a que Sandy optará por el aborto; por ello, cuando ésta quiere confesar la verdad a Amadeo, en la telenovela se enfatiza que la alegría más grande del mundo es tener a la familia unida.

S: Ary, intenté decirle la verdad a Amadeo, pero ahí estaba él hablando de lo felices que están, de la familia que son ahora. No pude, no pude decir nada.

Ar: Pero Amadeo jtiene que saberlo! ¿No piensas decírselo?

$\mathrm{S}$ : Ya lo decidí, no le pienso decir. No le voy a decir nada.

Ar: Sandy, pero tú no te puedes aventar esto sola.

Capítulo 160 (06/10/08).

Sandy no acepta la bendición de ser madre, ya que ese bebé "se equivocó de momento" y al llegar no sólo le provocó un mal sino que también le quitó el deseo de ser madre. Ante esto, Ary se posicionó como una autoridad religiosa al dejarle claro "los hijos no se buscan simplemente vienen".

Es decir, cuando una mujer se embaraza "no hay marcha atrás". En consecuencia, abortar, como verbo u acción, no existe en el diálogo porque su significado es suplantado por el verbo "deshacer", esto implica una carga simbólica más fuerte porque técnicamente Sandy destruiría algo que ya está formado: vivo.

Pese a que desde la ficción queda claro que la mujer no tiene derecho a "decidir sobre su cuerpo", Sandy piensa que lo mejor para ella es acudir a una clínica donde puede interrumpir legalmente su embarazo. 
De esta manera, conjuntando realidad con la ficción, Sandy realiza diversas acciones que técnicamente empatan con el procedimiento legal marcado en la LILE; por ejemplo, llama a una clínica para hacer una cita, confiesa tener las semanas legales para abortar (menos de 12)15 y acude a una hospital para hacerlo.

Alma de Hierro de una forma muy velada trató de exponer que el ejercicio de este derecho es algo muy simple y rápido como “descolgar el teléfono, llamar y hacer una cita" e, incluso, en la espera que le dan a Sandy se deja entrever que la demanda por abortar es tal que una mujer tiene que esperar "una semana" para resolver su problema. En la vida real, entre que una mujer solicita la información, acude a terapia psicológica y a un chequeo médico para corroborar el tiempo de gestación (ultrasonido) pasan alrededor de dos semanas.

A: Sandy deberías de distraerte un poco.

S: ¿Cómo quieres me distraiga, cómo quieres que esté contenta? ¡Voy a deshacerme de mi hijo y tú quieres que me divierta!

Ar: No Sandy, piensas así porque estás confundida, llena de rencor $\ldots y$ deshacerte de tu hijo, Sandy, te va dejar una huella imborrable en tu alma.

Capítulo 167 (15/10/2008).

El acto de eliminar lo "ya hecho" genera en Sandy una depresión que le impide "estar contenta" y no tendría porque estarlo, pues desde la telenovela lo que ella piensa hacer es una acción que sólo una persona "llena de rencor" podría hacer, puesto que abortar narrativamente significa "tener una huella en el alma".

No obstante, Sandy -en compañía de Ary- acude a la clínica para realizarse el aborto. Este lugar, a diferencia, de los escenarios donde las mujeres de las telenovelas mexicanas acudían para interrumpir su embarazo -recuérdese el caso de la clásica telenovela El Derecho de

15 Después de las 12 semanas de gestación, la mujer que aborte -excepto por razones de salud- será acreedora a una sanción penal que va de cuatro meses a un año de prisión; igual que en las legislaciones conservadoras que penalizaron el aborto. 
nacer- no era un sitio lúgubre sino una clínica iluminada y limpia donde trabajan enfermeras (Enf) y médicos (Med).

Alma de Hierro representó a la LILE como una acción práctica que no requiere de mayores requisitos, ya que en ningún momento Sandy comenta en la clínica las razones por las cuáles desea interrumpir su embarazo, nunca se le pide información personal -salvo sus semanas de embarazo- e incluso ella no firma el formato de "Consentimiento Legal de Interrupción del Embarazo" que es la constancia jurídica que da legalidad a la práctica abortiva.

Med: Bueno, ahora sí estamos listos, ya podemos empezar.

S: No, ya no quiero. Sáquenme de aquí. ¡No, quítenme eso, quítenmelo!

Capítulo 171 (21 /10/2008).

De pronto, Sandy decide que no puede "deshacer" lo que se ha hecho con amor y pide a Ary que la saque de ese lugar donde se "deshace el amor y los problemas".

S: ¡Ary, sácame, sácame de aquí, por favor!

Med: Discúlpeme, pero no está en condiciones de irse.

Ar: ;Usted cállese, la que decide es ella!

Capítulo 172 (22/10/2008).

Al final, los recursos morales y religiosos -vertidos en lo narrativotuvieron efecto porque Sandy defendió la vida de su hijo al "abortar y deshacerse" de la ley en el mismo escenario que la vuelve legal: la clínica social. Ganó el "derecho a la vida", ${ }^{16}$ porque los médicos no son los que deciden sino la mujer.

En este fragmento, sí se respetó la capacidad de Sandy para decidir sobre su cuerpo, ya que la decisión era a favor de la vida y de lo que es correcto para la ficción. Cuando Sandy recuperó la consciencia únicamente pidió perdón a su hijo "por la estupidez que iba a ser" (Capítulo $172,22 / 10 / 2008)$.

16 Tal y como pedía el papá del productor de Alma de Hierro, Chespirito, al encabezar una campaña a favor de la vida con un eslogan muy directo: "Abortemos la Ley, no la Vida". 
Dos días después, la misma Sandy, personificada por la actriz Angelique Boyer, expresó: “A estas alturas todas las mujeres sabemos cómo se forma un bebé y tenemos consciencia del riesgo que conlleva tener relaciones sexuales. No tolero la ignorancia, y el aborto es una salida fácil” (Santos, 2008).

La representación de la LILE dentro de Alma de Hierro avala el alto porcentaje de mujeres (40\%) que se acerca a las instancias de Salud del Distrito Federal para solicitar información y decide, después de algunas pláticas y exámenes, no practicarse un aborto. La gran diferencia es que en la telenovela esto se magnificó a tal punto que el ejercicio ciudadano y el derecho en sí mismo quedó relegado a una práctica rápida y sin consciencia que realizan mujeres desesperadas con el aval de la ley.

\section{LSC: "PODRÁN SER LEGALES, PERO NO MORALES"}

El 16 de marzo de 2007, 570 parejas (previamente registradas ante la Dirección General Jurídica y de Gobierno del Órgano Político-Administrativo del Distrito Federal) se unieron mediante el acto jurídico que establece la Sociedad de Convivencia. Ese mismo día, "Arnaldo y Julio" también tomaron la determinación de unir sus vidas, sólo que éstos eran personajes de la telenovela Amar sin límites (Televisa, 2006). Unos años después Alma de Hierro retoma la temática gay y cambia el clásico final de las telenovelas mexicanas al colocar una boda entre dos hombres.

\section{Contexto ficcional}

Ignacio Hierro (Ig) era un estilista maduro que no se perdonaba el haber abandonado, 25 años atrás, a su esposa e hijos por otro hombre. Cuando sus hijos lo perdonaron, éste reprimió su orientación y sus preferencias sexuales, ya que prefirió tener el "amor de su familia" que el de una pareja.

\section{¿OPCIÓN NARRATIVA O COYUNTURA FICCIONAL?}

El 28 de junio de 2008, la marcha por el orgullo de la Comunidad LGBT, que se celebra en el Distrito Federal, cumplió 30 años. Alma de Hierro fue parte del evento al grabar ahí una escena muy particular.

Esta marcha más allá de la festividad funciona como un espacio de visibilidad para denunciar la violación a los derechos de la Comunidad. 
No obstante, esta parte no apareció, ya que las escenas mostradas sólo hicieron énfasis a la festividad.

En ese contexto, Alma de Hierro grabó una entrevista que le hizo un reportero $(\mathrm{Re})$ a Hierro $(\mathrm{H})$, hombre maduro y machista que fue el personaje principal de la telenovela, para preguntarle qué significaba para él "ser gay".

Re: ¿Qué significa para usted ser gay?

H: No, no. ;Yo no soy gay!

Re: Todos decimos eso al principio, pero después, ¡Nos encanta!

H: ¿Esto va a salir en la televisión?

Re: Así es, ¡anímese es su oportunidad para salir del clóset!

H: ¡Papá, ayúdame con esto!

Re: Vemos como un integrante de la comunidad gay le dice cariñosamente "papá” a su pareja.

¿Eso demuestra que se pueden demostrar su cariño

a pesar de las diferencias sexuales!

H: ¡No, papá! Por favor, aclara esto. Tantos años de ser macho y acabar así.

Re: Ni se preocupe, ya ve que dicen que la "homosexualidad es cosa de machos"; mejor vamos a platicar con su pareja: ¿Cómo ha cambiado su situación en lo sexual?

Ig: ¡No, es mi hijo! ¡Es mi hijo!

$\mathrm{H}$ : Perdóneme pero yo soy casado con todas las de la ley, tengo papeles y todo.

Re: Claro éste es uno de los principales estandartes: las sociedades de convivencia, con lo cual se ha concedido el reconocimiento legal de las parejas homosexuales.

Hi: No, no. Yo nada más aclaro que vine apoyarlos en todo a ustedes.

Re: Un ejemplo de un luchador de derechos, ¿desde cuándo?

Hi: No, no. Rafa diles que lo mío son las faldas.

Re: ¿iAh ¿usted es travesti!?

Capítulo 157 (04/07/2008).

En este fragmento destaca la oposición simbolizadora entre el "ser gay" y el "ser macho" representadas por el papel que asume el reportero y la defensa que hace Hierro de sus cuestionamientos. El reportero en 
un plan "incluyente" construye un discurso discriminatorio y/o peyorativo hacia la comunidad homosexual, acción que Hierro también asume de una forma velada porque minimiza lo homosexual anteponiendo los valores machistas que destacan su virilidad.

Lo de Hierro son "las mujeres y las faldas" y no las manifestaciones "amorosas" que los homosexuales pueden realizar "a pesar de sus preferencias" y que de acuerdo con el reportero más que a lo sentimental o lo legal se abocan a lo sexual.

Cuando el reportero habla de la LSC como una instancia que brinda "certeza legal y social" a las uniones gay inmediatamente Hierro (sin oposición de la comunidad gay representada) precisa que él "sí está casado con todas las de la Ley", argumento que separa simbólica y moralmente la unión por Sociedad de Convivencia de la unión entre un hombre y una mujer. Por ello, se asume que la LSC "podrán ser legal, pero no moral", como mencionó el Episcopado Mexicano cuando se aprobó constitucionalmente esta legislación.

El reconocimiento legal (ciudadanía civil) y social (ciudadanía social) de la LSC que se hizo en la ficción dejó en claro que existen otros valores morales más importantes para la determinación del estatus moral y legal de los homosexuales, pues más que incluirlos se les tolera narrativa y comercialmente.

Los gay, como ciudadanos, ante el acoso del reportero fueron incapaces de defender sus derechos porque jamás existió - de su parte- una defensa a su orientación sexual y a la libre manifestación de sus ideas, pues de forma pasiva aceptaron la discriminación que recibieron de parte del reportero y del mismo Hierro. Esta misma línea fue la que se siguió durante toda la trama, ya que cuando Ignacio decidió abrirse a una nueva relación constantemente, desde la narrativa, se le recordaba que su "derecho a ser feliz", palabras con las que se resumió que el derecho ciudadano a la unión gay era directamente proporcional a la vergüenza que esto podía ocasionarle a su familia.

\section{La opción narrativa}

A mediados de 2009, la Comunidad LGTB en México realizó un movimiento solicitando se modificara el Código Civil del Distrito Federal para permitir el "matrimonio civil" entre personas del mismo 
sexo. ${ }^{17}$ Con ello, los homosexuales podrían ser acreedores de los mismos derechos y obligaciones que los matrimonios heterosexuales, incluida la posibilidad de adopción. Después de un arduo proceso, las modificaciones se aprobaron el 21 de diciembre de 2009.

Esto desencadenó múltiples controversias legales en todo el país, a tal punto que la SCJN nuevamente tuvo que actuar para dar constitucionalidad a la ley y pedir que dicha legislación fuera respetada y validada en todo el territorio mexicano.

Lo cierto es que, dos meses antes, de que el matrimonio civil entre personas del mismo sexo fuera aprobado, ya las telenovelas planteaban cuáles podrían ser las limitaciones sociales que personas del mismo sexo tendrían que afrontar si decidían unirse legalmente: a) el rechazo de la familia, b) la no validación social, pues más allá de lo legal de la unión ésta no sería avalada por la Ley divina y c) la jerarquización de sus derechos con base en los valores morales dominantes.

Así quedó plasmado en Alma de Hierro cuando Ignacio en varias ocasiones tuvo que esconder o terminar sus relaciones amorosas porque éstas causaban vergüenza y dolor a su familia.

La aceptación e inclusión narrativa de los derechos de los homosexuales en la ficción no garantizó que "ellos" (los terceros discursivos) pudieran actuar en consecuencia, pues en Alma de Hierro los impedimentos personales de Ignacio nada tenían que ver con la falta de certeza jurídica -que al final se conquistó cuando se unió con Abraham en sociedad de convivencia- sino con el entramado simbólicocultural que se tejió para que éste se sintiera obligado a suprimir su orientación sexual.

Es decir, si los homosexuales viven juntos sin ser convivientes, lo que están haciendo es un engaño, pero sí lo hacen por la vía legal, son discriminados porque su enlace jurídico jamás será igual a la unión entre el hombre y la mujer.

17 La diferencia entre la sociedad de convivencia y el matrimonio civil, es que en la primera es posible la unión más no se conceden a los convivientes todos los derechos que el matrimonio civil por ley garantiza: adopción, derechos de manutención, patria potestad y separación de bienes; por citar algunos. 
Al final, como lo mencionó Rafael Inclán (actor que encarnó a Ignacio) lo que se presentó en Alma de Hierro: "No fue un casamiento sino una relación de convivencia" (Trujillo, 2009). Por ello, qué más daba si narrativamente no se concluyó la unión entre Abraham e Ignacio si lo importante era mostrar que "eso también pasa en la sociedad", como precisó el productor de la telenovela, Roberto Gómez Fernández.

Esta telenovela concentró el debate social del "matrimonio gay" bajo una supuesta inclusión narrativa que si bien no inhibió el derecho, como en la LILE, si dotó a éste de una serie de consecuencias sociales y culturales (nunca legales).

El inhibido aquí, además del derecho, fue el ciudadano, pues en Alma de Hierro nunca se habló de la trascendencia de la unión por Sociedad de Convivencia (tampoco tenía que hacerse), ya que lo importante era delimitar simbólica y culturalmente en la ficción (y quizá también fuera de ella) lo qué es y no es una verdadera unión civil.

\section{CONCLUSIONES: “TELENOVELAS VEMOS}

\section{CIUDADANOS NO SABEMOS"}

Las representaciones ciudadanas vertidas en Alma de Hierro con relación a la LILE y LSC tienen diversas lecturas que comprueban que más allá de la aparente apertura narrativa/discursiva y la reconfiguración del modelo Televisa, sigue predominando en la ficción mexicana una fuerte carga moral y religiosa que se manifiesta de distintas maneras para cada uno de los derechos analizados.

En el caso de la LILE estos valores son evidentes porque en todo momento el discurso fue construido para anteponer a la legalidad y a los derechos de la mujer: el derecho a la vida. En la LSC, el tratamiento narrativo/discursivo apostó por representar un proceso instituyente de "aparente" defensa; es decir, en todo momento se manifestó que "incluso" los homosexuales tenían derecho a ser felices y unir sus vidas. Cuestión que al final quedó sin efecto cuando desde una dimensión cultural y social de la ciudadanía se construyó no sólo la identidad homosexual sino también el tipo de relaciones que éstos podrían tener.

Alma de Hierro, en ambos casos, apostó por no ocultar la existencia legal de los derechos ni tampoco los posicionamientos que se tenían 
hacia ellos. Al contrario, los colocó y conjuntó como parte del discurso ficcional, de tal manera que pareciera que todos esos discursos intertextuales formaban parte de las preocupaciones, prácticas y discursos de sus ciudadanos de ficción.

La telenovela interpeló a la razón vía la emotividad y a partir de esto construyó un discurso donde el drama de esos otros ciudadanos puede semejarse a situaciones vividas o por vivir de sus televidentes; es decir, si se parte de que la lógica de producción se cruza con la lógica de consumo, como precisa Martín-Barbero (1988), y que éstas a su vez son interceptadas por los discursos de poder y placer que dominan el entramado mediático (Meyrowitz, 2008 y Castells, 2009), es posible entender que las narrativas ficcionales buscan situarse al centro del debate social no generando sino potencializando un nuevo discurso sobre la cosmovisión político-institucional de la televisora -en este caso Televisa- dentro de las situaciones ficcionales de sus personajes.

Por eso, no fue casualidad que cuando más a debate en la realidad estaban los derechos en las esferas sociales, políticas y mediáticas, la telenovela decidiera llevarlos a su mundo ficcional. Con ello, la televisora podría trasladar la narrativa mediática construida en sus noticieros a un nuevo texto donde de forma más clara podría manifestar su postura sin riesgo a perder la "objetividad de su información".

Las moralejas ficcionales que se construyeron con relación a los derechos analizados no negaron su existencia; al contrario, lo que se buscó -como estrategia política e institucional-dentro de las telenovelas, fue inhibir tanto al derecho como al ciudadano no por omisión, como ocurría anteriormente, sino por una sobre representación.

Una vía de análisis para entender esto sería revisar la agenda que en un tiempo determinado construyan las telenovelas mexicanas, ya que podría dar algunas pistas sobre cómo la realidad social y sus múltiples problemáticas se van insertando en el discurso ficcional con la intención (institucional y política de las televisoras) de generar desde ahí discursos muy precisos que en sí mismos ya ofrecen a la audiencia un ejemplo de las consecuencias sociales y personales que tendría para ellas ejercer algún derecho, votar por determinado partido, apoyar tal movimiento social o no aceptar las disposiciones o planes gubernamentales. 


\section{ANEXO}

\section{FICHA TÉCNICA DE ALMA DE HIERRO}

TÍTULO ORIGINAL: SON DE FIERRO DE ADRIAN SUAR (ARGENTINA, 2008)

Año de producción:

2008

\begin{tabular}{ll}
\hline Número de capítulos: & 392 \\
Duración de capítulos: & 30 minutos, de 10:00 a 10:30 p.m. \\
Inicio-Final & $25 / 02 / 08$ al 28/08/09 \\
Franja de emisión: & Prime Time \\
Audiencia promedio: & $22.68 \%$ \\
Productora: & Televisa (Canal 2) \\
Productor: & Roberto Gómez Fernández \\
Guionistas: & Ximena Suárez, Aída Guajardo \\
Elenco: & Alejandro Camacho, Blanca Guerra, \\
& Jorge Poza y Angelique Boyer \\
\hline
\end{tabular}

Fuente: IBOPE (2009).

\section{Bibliografía}

Benhabid, S. (2004). The rights of others. Cambridge: University Press. Castells, M. (2009). Comunicación y poder. España: Alianza Editorial. Cortina, A. (2003). Ciudadanos del mundo. Hacia una teoría de la ciudadanía. Madrid, España: Alianza Editorial.

Dorcé, A. (2005). The politics of melodrama: The historical development of the Mexican telenovela, and the representation of politics in the telenovela Nada Personal, in the context of transition to democracy in Mexico. Tesis de doctorado no publicada. University of London, Londres, Inglaterra.

Fairclough, N. (2008). El análisis crítico del discurso y la mercantilización del discurso público: las universidades. Discurso y sociedad, 2 (1), 107-185.

Franco, D. (2010). ¿Ciudadanos de ficción? Representaciones, prácticas y discursos ciudadanos en las telenovelas mexicanas. El caso Alma de Hierro. Tesis de Maestría no publicada. Universidad de Guadalajara, Guadalajara, México. 
Franco, D. \& Orozco, G. (2010). La telenovela de la ciudadanía y la ciudadanía en la telenovela. En Z. Rodríguez (Coord.), Entretejidos comunicacionales. Aproximaciones a objetos y campos de la comunicación (pp. 65-90). México: UdeG.

González, J. (Comp.). (1998). La cofradia de las emociones (in)terminables miradas sobre telenovelas en México. México: UdeG.

Heater, D. (2007). Ciudadanía. Una breve historia. España: Alianza Editorial.

Instituto Brasileño de Opinión Pública-IBOPE. (2009). Anuario 2009. Recuperado el 10 de agosto de 2009 de http:/www.ibope.com.mx/ biblioteca/anuario.php.

Instituto Brasileño de Opinión Pública-IBOPE (2010). Anuario 2010. Recuperado el 24 de junio de 2010 de http://www.ibope.com.mx/ biblioteca/anuario.php.

Martín-Barbero, J. (1988). De los medios a las mediaciones: comunicación, cultura y hegemonía. México: Andrés Bello.

Martín-Barbero, J. \& Muñoz, S. (Coords.). (1992). Televisión y melodrama. Géneros y lecturas de la telenovela en Colombia. Bogotá, Colombia: Tercer Mundo Ediciones.

Martín-Barbero, J. \& Rey, G. (Coords.). (1999). Los ejercicios del ver. Hegemonía audiovisual y televisiva. Barcelona, España: Gedisa.

Marshall, T.H. (1998). Ciudadanía y clase social. Madrid, España: Alianza Editorial.

Mazziotti, N. (Comp.). (1996). La industria de la telenovela. La producción de ficción en América Latina. Buenos Aires, Argentina: Paidós.

Mazziotti, N. (2006). Telenovela: industria y prácticas sociales. Colombia: Norma.

McCombs, M. \& Shaw, D. (1972). The agenda-setting function of mass-media. EE.UU.: Public Opinion Quaterly.

Meyrowitz, J. (2008). Power, pleasure, patterns: Intersecting narratives of media influence. The Journal of Communication, 58, 641-663.

Orozco, G. (2006). La telenovela en México: ¿de una expresión cultural a un simple producto para la mercadotecnia? Comunicación y Sociedad, 6, 11-35. 
Orozco, G.; Huizar, A.; Franco, D. \& Hernández, F. (2010). México: la ficción se desinhibe. Naturalización de publicidad, propaganda, violencia y ciudadanías en las telenovelas. En G. Orozco, \& M. Vassallo (Coords.), Anuario OBITEL 2010. Convergencias y transmediación de la ficción televisiva (pp. 304-337). Brasil: Globo Editora.

Pocock, J. (1995). The ideal of citizenship since clasical times. En Beiner, R. (Ed.), Theorizing citizenship (pp. 35-55). Nueva York, EE.UU.: University of New York Press.

Ramírez Sáiz, J. (2007). Descentramiento de la ciudadanía nacional. México: ITESO.

Reguillo, R. (2003). Ciudadanía cultural. Una categoría para pensar en los jóvenes. Renglones, 55, 27-36.

Rodríguez, T. (2009). Sobre el potencial teórico de las representaciones sociales en el campo de la comunicación. Comunicación y Sociedad, 11, 11-36.

Rosaldo, R. (1994). Cultural citizenship and educational democracy. Cultural Anthropology, 9 (3), 402-421.

Santos, G. (2008). Angelique Boyer contra el aborto. En Suplemento Zócalo. Recuperado el 2 de febrero de 2009 de http://www.zocalo. com.mx/images/uploads/archive/122495040576.pdf.

Tufte, T. (2007). Soap operas y construcción de sentido: mediaciones y etnografía de la audiencia. Comunicación y Sociedad, 8, 89-112.

Trujillo, H. (2009). Rafael Inclán, satisfecho con su personaje. En esmas.com, página oficial de Alma de Hierro. Recuperado el 3 de octubre de 2009 de http://www.esmas.com/alma-de-hierro/noticias/798201.html.

Vassallo, M. (2004). Telenovela: internacionalización e interculturalidad. Brasil: Universidad de San Paulo.

Fecha de recepción: 08/03/2011. Aceptación: 13/05/2011. 